\title{
Correction to: IL-17A Induces MIP-1a Expression in Primary Astrocytes Via Src/MAPK/PI3K/NF-kB Pathways: Implications for Multiple Sclerosis
}

\author{
Hongwei Yi ${ }^{1}$ Y Ying Bai ${ }^{1} \cdot$ Xinjian Zhu ${ }^{1} \cdot{\text { Lin } \operatorname{Lin}^{1} \cdot \text { Lei Zhao }}^{1} \cdot$ Xiaodong $\mathrm{Wu}^{1} \cdot$ Shilpa Buch $^{2} \cdot$ Longxin Wang $^{3}$. \\ Jie Chao ${ }^{4,5} \cdot$ Honghong Yao ${ }^{1,5}$ \\ Published online: 6 October 2020 \\ (C) Springer Science+Business Media, LLC, part of Springer Nature 2020
}

Correction to: J Neuroimmune Pharmacol (2014) 9:629-641 https://doi.org/10.1007/s11481-014-9553-1

The original version of this article unfortunately contained a mistake in Fig. 5B. The corrected Fig. 5 is given below. The authors declare that this amendment does not change the result or conclusion of the paper, and apologize for this oversight.

The online version of the original article can be found at https://doi.org/ 10.1007/s11481-014-9553-1

Honghong Yao

yaohh@seu.edu.cn

Jie Chao

chaojie@ seu.edu.cn

1 Department of Pharmacology, Medical School of Southeast

University, Nanjing, China

2 Department of Pharmacology and Experimental Neuroscience, University of Nebraska Medical Center, Omaha, NE, USA

3 Department of Urology, Jinling Hospital, Medical School of Nanjing University, Nanjing, China

4 Department of Physiology, Medical School of Southeast University, Nanjing, China

5 Department of Pharmacology, Medical School of Southeast University, Nanjing 210009, Jiangsu, China 

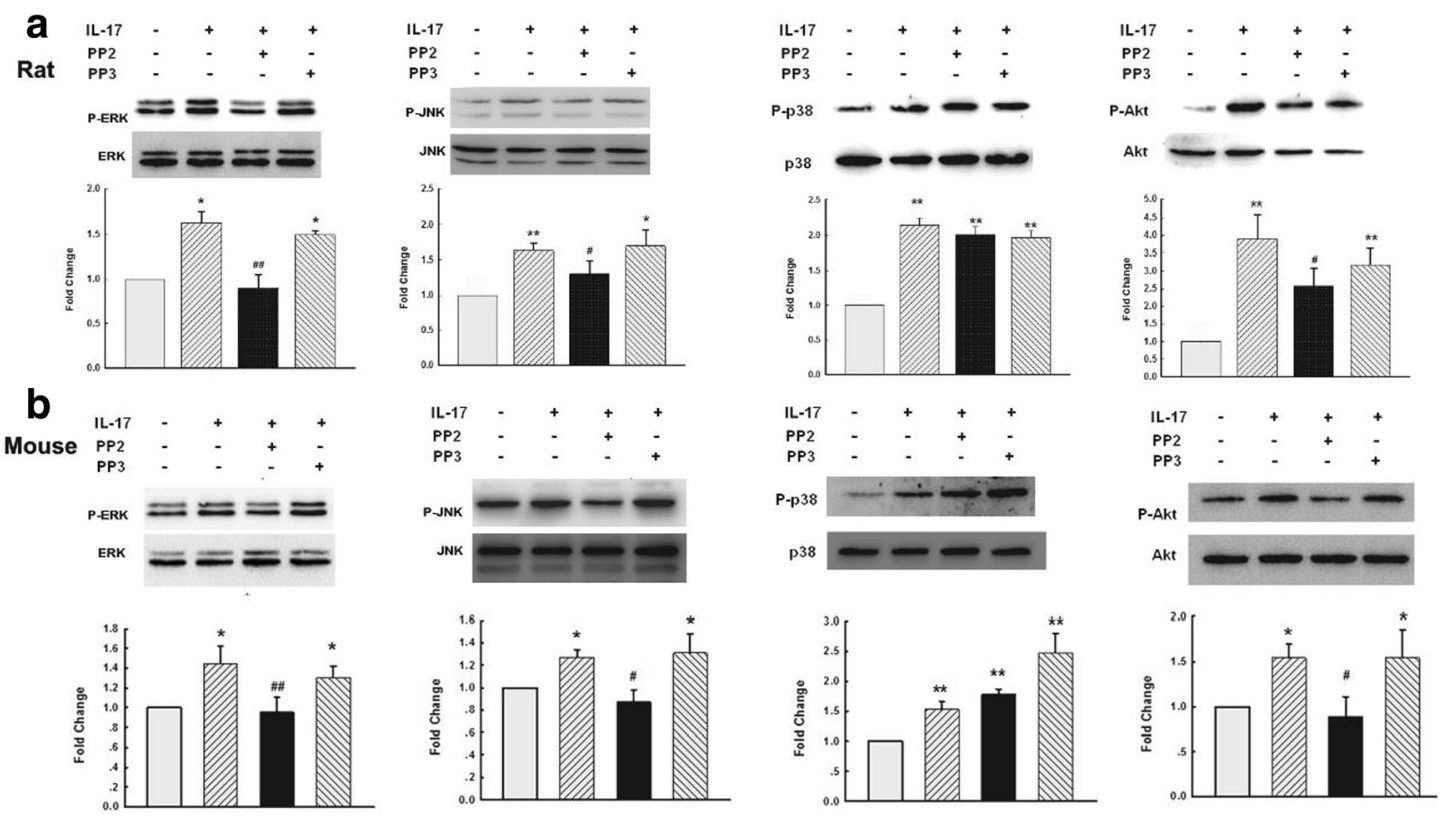

Publisher's Note Springer Nature remains neutral with regard to jurisdictional claims in published maps and institutional affiliations. 